\title{
Biocatalyzed Generation of Molecular Diversity: Selective Modification of the Saponin Asiaticoside
}

\author{
Daniela Monti, ${ }^{\mathrm{a}}$ Andrea Candido, ${ }^{\mathrm{a}, \mathrm{b}}$ M. Manuel Cruz Silva, ${ }^{\mathrm{c}}$ Vladimir Křen, ${ }^{\mathrm{d}}$ \\ Sergio Riva, ${ }^{\mathrm{a}, *}$ Bruno Danieli $^{\mathrm{b}}$ \\ a Istituto di Chimica del Riconoscimento Molecolare, C. N. R., Via Mario Bianco 9, 20131 Milano, Italy \\ Fax: (+39)-02-2850-0036, e-mail: sergio.riva@icrm.cnr.it \\ b Dipartimento di Chimica Organica e Industriale, Università degli Studi di Milano, Via Venezian 21, 20133 Milano, Italy \\ c Centro de Estudos Farmacêuticos, Lab. Química Farmacêutica, Faculdade de Farmácia, Universidade de Coimbra, Rua \\ do Norte 3000-295, Coimbra, Portugal \\ d Institute of Microbiology, Laboratory of Biotransformation, Academy of Sciences of the Czech Republic, Vídeňská 1083, \\ 14220 Prague 4, Czech Republic
}

Received: January 25, 2005; Accepted: March 16, 2005

Supporting Information for this article is available on the WWW under http://asc.wiley-vch.de/home/.

\begin{abstract}
An array of different derivatives of the complex ursane-type triterpene glycoside asiaticoside (1), a saponin component isolated from the perennial herb Centella asiatica, was generated by exploiting the stereo-, regio- and site-selectivity of four groups of enzymes (glycosidases, glycosyltransferases, lipases and laccases). A library of extracellular $\alpha$-L-rhamnosidases (31 different items) was obtained by screening 16 different fungal strains under different cultivation conditions, and several of these preparations catalyzed the derhamnosylation of asiaticoside. Specifically, the enzymes produced by Fusarium oxysporum were selected for the synthesis of derhamno-degluco-asiaticoside (2) and also of derhamno-asiaticoside
\end{abstract}

(3), by in situ glucose-inhibition of contaminating $\beta$ D-glucosidases. $\beta$-1,4-Galactosyltransferase from bovine milk was subsequently used for the galactosylation of the two asiaticoside derivatives $\mathbf{2}$ and $\mathbf{3}$, using $20 \% \mathrm{v} / \mathrm{v}$ DMSO as a cosolvent in order to increase substrate solubility. Finally, new acylated and oxidized derivatives of asiaticoside were also prepared by exploiting the lipase from Candida antarctica (Novozym 435) and the laccase from Trametes pubescens, respectively.

Keywords: asiaticoside; biotransformations; combinatorial biocatalysis; enzyme catalysis; glycosidases; glycosides

\section{Introduction}

Natural products constitute a relevant economic resource for the pharmaceutical, cosmetic and food industries as they are an unsurpassed source of bioactive compounds, useful to improve the well-being and the quality of life of humans. Many biologically active compounds are glycosides, ${ }^{[1]}$ and clear correlations between the presence of specific sugar residues and the biological activity of these molecules have been shown in many cases. ${ }^{[2]}$ For example, asiaticoside (1), a saponin component isolated from Centella asiatica with an ursane-type triterpene structure carrying a trisaccharide unit (Scheme 1), has been shown to have anti-inflammatory properties by stimulating wound-healing processes via fibroblast proliferation and collagen and glycosaminoglycan synthesis. ${ }^{[3-5]}$ Moreover, some asiaticoside derivatives possess strong neuroprotective effects against beta-amyloid-induced neurotoxicity by antiapoptotic and antioxidative injury mechanisms. ${ }^{[6]}$

In the last years it has been shown that biocatalysis offers a number of key advantages over chemical synthesis when working on complex molecules, advantages based on the chemo-, regio- and stereoselectivity of enzymes and on the possibility to carry out reactions under mild conditions. ${ }^{[7]}$ Even in the cases of simple transformations, for example, an acylation reaction, enzymatic chemo- and regioselectivity often allow one to avoid the protection-deprotection steps embodied in the usual chemical routes, once both the biocatalyst and the reaction conditions have been carefully selected.

Here we report on the use of four groups of enzymes (glycosidases, glycosyltransferases, lipases and laccases) for the preparation of a series of specific derivatives of asiaticoside by modification of its glycosidic moiety. The selected enzymes furnished derivatives with differ- 
ent characteristics, for instance, more hydrophilic in the case of laccases and glycosyltransferases and more lipophilic in the case of glycosidases and lipases, thus allowing the generation of molecular diversity that can be exploited to modulate the bioactivity and bioavailability of the starting substrate.

\section{Results and Discussion}

The sugar moiety of asiaticoside is a trisaccharide containing an $\alpha$-L-rhamnopyranoside linked to the disaccharide gentiobiose. The selective modification of this carbohydrate unit was initially attempted by a combined use of glycosidases and glycosyltransferases (see Scheme 1).

We have recently described the preparation of a library of extracellulary $\alpha$-L-rhamnosidases by growing several fungi in the presence of different inducers (Figure 1), and we have exploited this biocatalysts collection for the selective derhamnosylation of natural glycosides. $^{[8]}$
A new screening of these 31 different enzymatic samples allowed the identification of 10 preparations, originating from 4 different fungi, that were able to hydrolyze asiaticoside. As expected, the contaminating $\beta$-D-glucosidases present in these crude samples were also active on the derhamnosylated intermediate derivative 2 (DeRha-Asia) and therefore, in all cases, the final products detected by TLC were either the fully deglycosylated aglycone (asiatic acid, 4) or the monosaccharidic derivative derhamno-degluco-asiaticoside 3 (DeRhaDeGlc-Asia, Figure 2 and Table 1).

As the preparation from Fusarium oxysporum $\mathrm{CCF}$ 906 induced with rutin did not show the formation of asiatic acid, this sample was chosen for a preparative-scale reaction, whose HPLC chromatogram is reported in Figure $3 \mathrm{~A}$.

The monoglycosidic compound 3 was isolated in $47 \%$ yield and its structure confirmed by the respective mass and NMR data. The ESI-MS showed a molecular mass of 673 a.m.u., corresponding to the sodium salt of a monoglucosylated asiaticoside. In comparison to the starting substrate asiaticoside, the NMR spectra of $\mathbf{3}$ were lack-
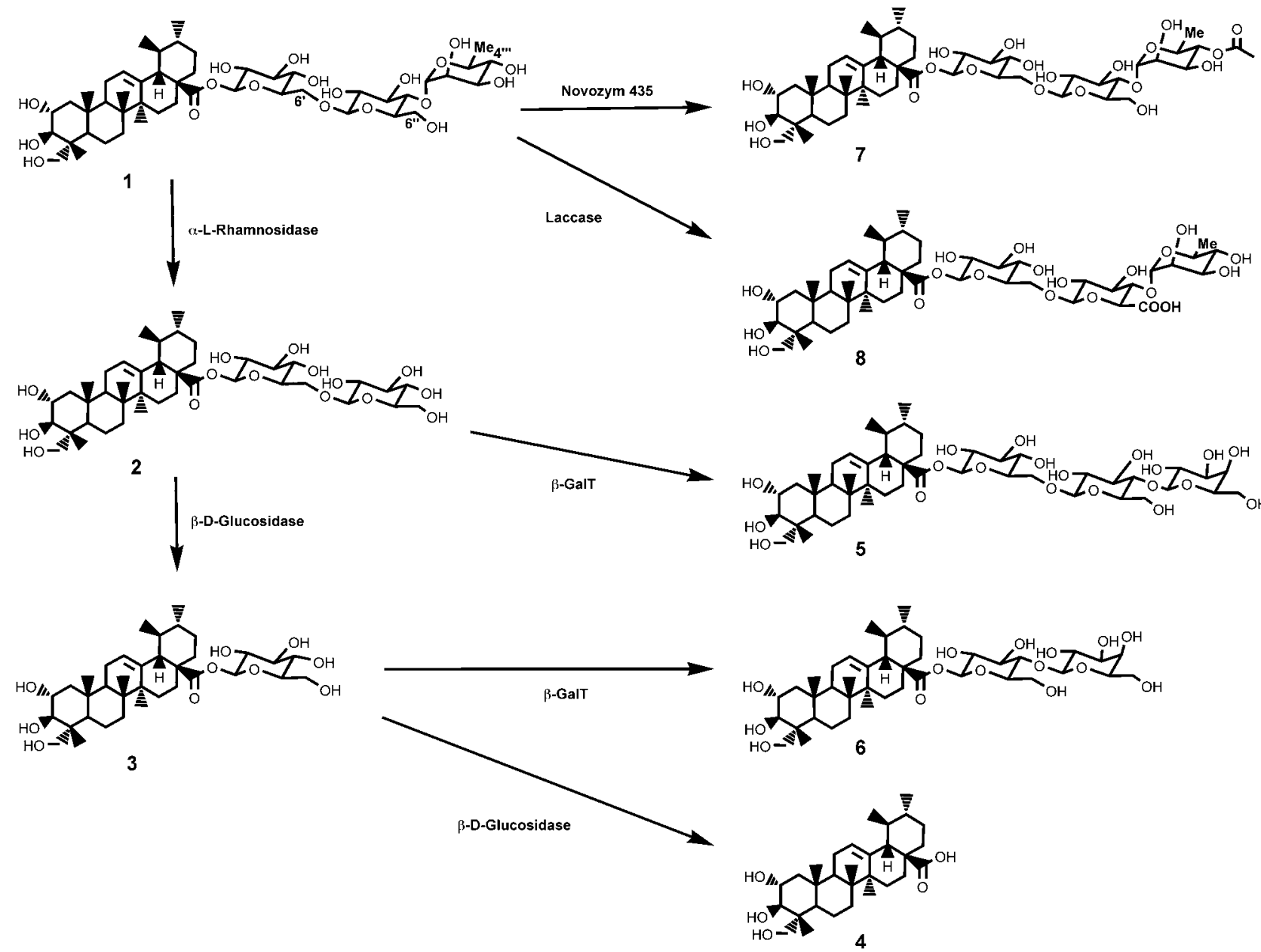

Scheme 1. Enzymatic modification of the natural glycoside asiaticoside (1). 


\begin{tabular}{|c|c|}
\hline & \\
\hline Acremoricon persicmen & CCF 1850 \\
\hline Aspergillus aculeatus & CCF 108 \\
\hline Aspergillus aculeatus & CCF 3134 \\
\hline Aspergillus aculeatus & CCF 3138 \\
\hline Aspergillus riger & CCIM K2 \\
\hline Aspergillus terreus & CCF 3059 \\
\hline Circinella muscae & $\operatorname{CCF} 2413$ \\
\hline Emericellanidulans & CCF 2912 \\
\hline Ewotium anstelociami & CCF 2323 \\
\hline Fusarizon oxysporum & CCF 906 \\
\hline Mortier ella alpina & CCF 2514 \\
\hline Mucor circinelloides grisea cyanus & CCIM \\
\hline Ponicilium oxalicun & $\operatorname{CCF} 2430$ \\
\hline Rhizopus arrhizus & CCF 100 \\
\hline Talaromyces flavus & CCF 2686 \\
\hline Trichoderma harzianzom & CCF 2687 \\
\hline
\end{tabular}

Inducers<smiles>OC1C2CCC(O2)[C@H](O)C1O</smiles>

(L)-Rhamunose

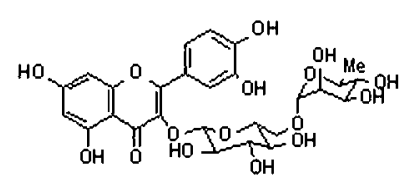

Rutin

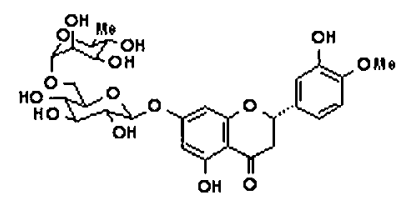

Hesperidin

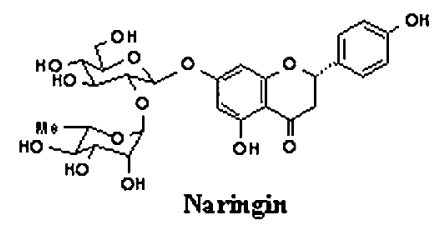

Figure 1. Fungal strains and inducers used for the generation of the $\alpha$-L-rhamnosidase library. CCF: Culture Collection of Fungi, Department of Botany, Charles University, Prague, Czech Republic; CCIM: Culture Collection of the Institute of Microbiology, Prague, Czech Republic.

ing of the signals of the L-rhamnopyranosyl and one of the two D-glucopyranosyl units. Selected diagnostic ${ }^{1} \mathrm{H}-\mathrm{NMR}$ signals of the only glucopyranosyl moiety linked to the aglycone were a doublet at $5.37 \mathrm{ppm}(J=$ $8.0 \mathrm{~Hz}$ ) due to the anomeric proton $\mathrm{H}-\mathrm{1}^{\prime}$ and two dd at $3.81\left(J_{1}=12.0\right.$ and $\left.J_{2}=2.3 \mathrm{~Hz}\right)$ and $3.70\left(J_{1}=12.0\right.$ and $\left.J_{2}=4.4 \mathrm{~Hz}\right) \mathrm{ppm}$ due to $\mathrm{H}-6_{\mathrm{a}}{ }^{\prime}$ and $\mathrm{H}-6_{\mathrm{b}}{ }^{\prime}$. Similarly, in the ${ }^{13} \mathrm{C}$-NMR spectrum, the signals of a single saccharidic unit were detected at $94.4\left(\mathrm{C}-1^{\prime}\right), 72.6\left(\mathrm{C}-2^{\prime}\right), 70.0(\mathrm{C}-$ $\left.4^{\prime}\right)$ and $61.3 \mathrm{ppm}\left(\mathrm{C}-6^{\prime}\right)$, together with two of the three

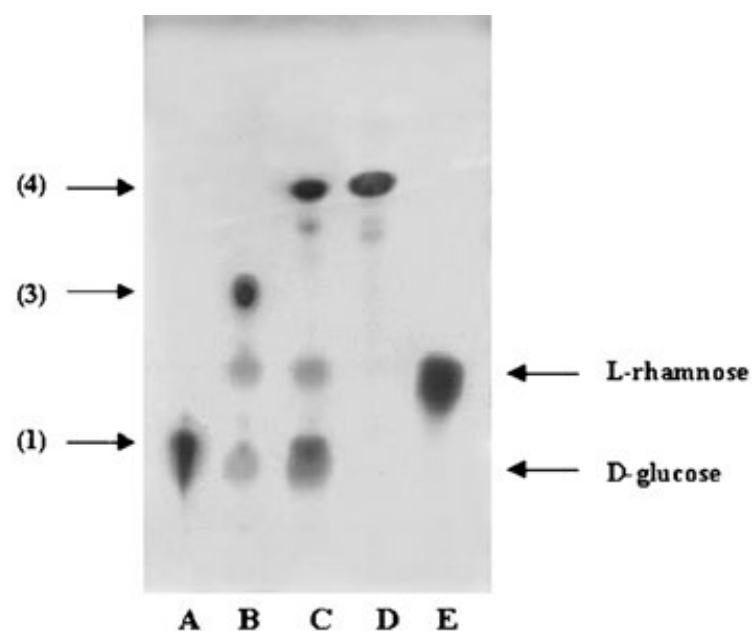

Figure 2. TLC analysis of selected reactions from the screening of the $\alpha$-L-rhamnosidase library. A) Asiaticoside; B) reaction with $\alpha$-L-rhamnosidase from Aspergillus terreus $\mathrm{CCF}$ 3059 induced with rhamnose; C) reaction with $\alpha$-L-rhamnosidase from Emericella nidulans CCF 2912 induced with hesperidin; D) asiatic acid; E) L-rhamnose.

signals at 77.3, 77.2 and $77.1 \mathrm{ppm}\left(\mathrm{C}-3^{\prime}\right.$ and $\mathrm{C}-5^{\prime}$; the third signal was due to the $\mathrm{C}-3$ of asiatic acid).

In order to isolate the gentiobiose derivative $\mathbf{2}$, it was necessary to overcome the limitation related to the nonhomogeneous nature of our enzyme preparations. In a usual approach, the more promising catalysts should have been purified using classical protein chromatography. However, in this specific case, we reasoned that the contaminating $\beta$-D-glucosidases could be inactivated by product inhibition. Accordingly, enzymatic hydrolysis was performed in the presence of $15 \% \mathrm{w} / \mathrm{v}$ glucose and we were pleased to find that a different product was formed with an intermediate polarity between $\mathbf{1}$ and $\mathbf{3}$ (Figure 3B). This compound was isolated in $46 \%$ yield and its structure confirmed by spectroscopic analysis. ESI-MS analysis gave the value of 835 a.m.u. for the molecular peak, corresponding to the expected value for the sodium salt of DeRha-Asia (2). The NMR spectra confirmed the presence of a gentiobiose unit and the lack of the L-rhamnopyranosyl moiety. Selected diagnostic ${ }^{1} \mathrm{H}$-NMR signals were two doublets at 5.33 and $4.36 \mathrm{ppm}$, due to the two anomeric protons $\mathrm{H}-\mathrm{1}^{\prime}$ and $\mathrm{H}-1^{\prime \prime}$, and four dd at 4.12 and 3.76, 3.87 and 3.67, due to $\mathrm{CH}_{2}-6^{\prime}$ and $\mathrm{CH}_{2}-6^{\prime \prime}$, respectively, while the signals due to the gentiobiose unit could be identified and assigned in the ${ }^{13} \mathrm{C}$-NMR spectrum (see Experimental Section).

Having selectively "trimmed" asiaticoside, we decided to attempt some enzymatic "grafting" exploiting the nowadays commercially available $\beta-1,4$-galactosyltransferase from bovine milk ( $\beta$-GalT). This enzyme is able to transfer regio- and stereospecifically a sugar unit, usually a galactopyranoside, from an activated UDP donor to the C-4-OH of an unprotected glucopyr- 
Table 1. Screening of the library of $\alpha$-L-rhamnosidases for asiaticoside modification.

\begin{tabular}{|c|c|c|c|}
\hline \multirow[t]{2}{*}{ Strain } & \multirow[t]{2}{*}{ Inducer } & \multicolumn{2}{|l|}{ Main Product } \\
\hline & & $\begin{array}{l}\text { DeRha-DeGlc } \\
\text { Asiaticoside (3) }\end{array}$ & $\begin{array}{l}\text { Asiatic } \\
\text { Acid (4) }\end{array}$ \\
\hline Aspergillus terreus CCF 3059 & $\begin{array}{l}\text { L-Rhamnose } \\
\text { Rutin } \\
\text { Hesperidin } \\
\text { Naringin }\end{array}$ & $\begin{array}{l}\mathbf{X} \\
\mathbf{X} \\
\mathbf{X} \\
\mathbf{X}\end{array}$ & \\
\hline Emericella nidulans CCF 2912 & $\begin{array}{l}\text { L-Rhamnose } \\
\text { Hesperidin } \\
\text { Naringin }\end{array}$ & $\mathbf{X}$ & $\begin{array}{l}\mathbf{X} \\
\mathbf{X}\end{array}$ \\
\hline Fusarium oxysporum CCF 906 & $\begin{array}{l}\text { Rutin } \\
\text { Naringin }\end{array}$ & $\mathbf{X}$ & $\mathbf{X}$ \\
\hline Talaromyces flavus CCF 2686 & Naringin & $\mathbf{X}$ & \\
\hline
\end{tabular}

anosyl acceptor to give the corresponding lactosyl derivative and UDP. ${ }^{[9]}$ Natural acceptors of this enzyme are either glucose itself or $N$-acetylglucosamine linked to a protein chain. However, in previous papers, we have shown that this enzyme is quite versatile concerning the aglycone moiety and therefore different natural glucopyranosides (i.e., colchicoside and ginsenosides) could be selectively galactosylated. ${ }^{[10]}$ As compounds 2 and 3 possess a free C-4-OH on their external glucopyranosyl moiety, both of them could be submitted to the action of $\beta-1,4-$ GalT. Due to the low solubility of these substrates, the reactions were performed in the presence of $20 \% \mathrm{v} / \mathrm{v}$ DMSO, a cosolvent that is well compatible with this enzyme and does not affect its activity and stability when used in this concentration. ${ }^{[11]}$ Both these biotransformations were successful and, as shown in Scheme 1, the corresponding galactosylated derivatives $\mathbf{5}$ and $\mathbf{6}$ could be isolated and characterized in the usual way. Both ESI-MS and NMR analysis confirmed the addition of a galactopyranosyl unit to $\mathbf{2}$ and $\mathbf{3}$ (isolated yields 47 and $9 \%$, respectively. For details see Experimental Section).

As a final step we considered the possibility to modify regio- and stereospecifically asiaticoside with enzymes different from the previous ones, that are naturally devoted to hydrolyze or to synthesize oligosaccharides. From our previous experiences in the modification of other natural compounds, the choice fell upon hydrolytic and oxidative enzymes.

The regioselective acylation of polyhydroxylated compounds catalyzed by lipases and proteases in organic solvents is a quite established methodology ${ }^{[12]}$ and previous studies have shown that enzymatic acylation of natural glycosides usually takes places on their sugar moieties even in the presence of reactive hydroxyl groups on the respective aglycones. ${ }^{[13]}$ Therefore, it was not surprising that the monoacylated derivatives isolated by reacting $\mathbf{1}$ (dissolved in THF) with vinyl acetate in the presence of different lipases or proteases were all characterized as sugar esters. The best results in terms

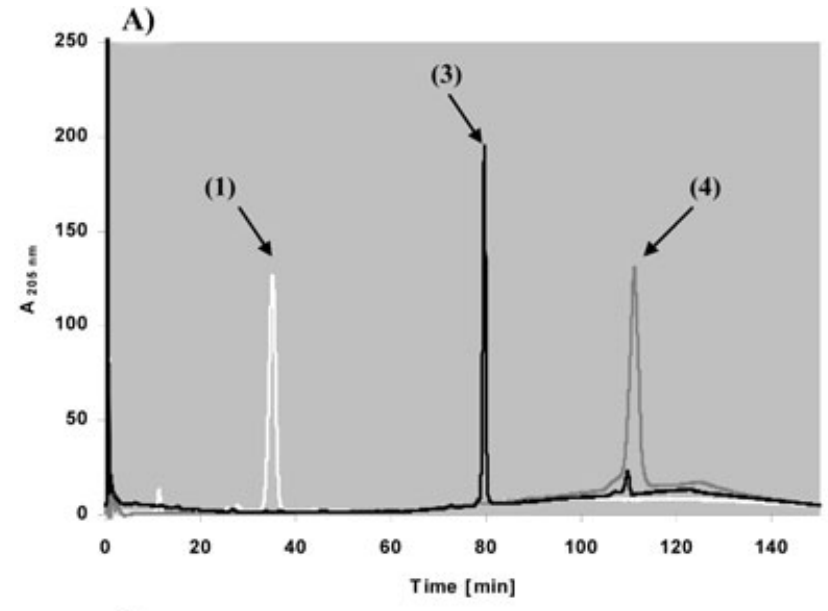

B)

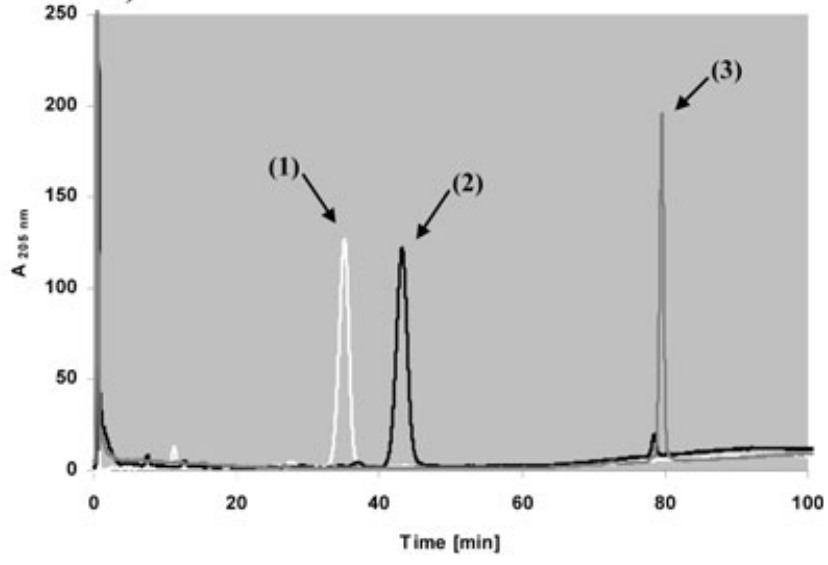

Figure 3. HPLC analysis of the reactions catalyzed by Fusarium oxysporum CCF 906 preparation induced by rutin. A) Hydrolysis of $\mathbf{1}$ to give $\mathbf{3}$ as the main product: black line, chromatogram of the reaction; white line and dark grey line, chromatrograms of the standard asiaticoside (1) and asiatic acid (4), respectively. B) Hydrolysis of $\mathbf{1}$ to give $\mathbf{2}$ as the main product: black line, chromatogram of the reaction; white line and dark grey line, chromatrograms of the standard asiaticoside (1) and DeRha-DeGlu-Asia (3), respectively. 
of selectivity were obtained with the lipase B from Candida antarctica (Novozym 435) and the single product (7) was isolated in 59\% yield. Its mass spectrum (1023 a.m.u.) indicated that 7 was a monoacetyl derivative. We have previously shown ${ }^{[14]}$ that Novozym 435 is able to acylate regioselectively the C-4-OH of L-rhamnopyranosyl derivatives, and this was also the case of asiaticoside. The ${ }^{1} \mathrm{H}-\mathrm{NMR}$ spectrum of $\mathbf{7}$ showed a triplet due to a proton shifted downfield at $4.94 \mathrm{ppm}$. Analysis of the bidimensional COSY spectrum of $\mathbf{7}$ clearly indicated that this signal was correlated to the signal (dq) at $4.31 \mathrm{ppm}$ due to $\mathrm{H}-5^{\prime \prime \prime}$. Additionally, the ${ }^{13} \mathrm{C}-\mathrm{NMR}$ spectrum of $\mathbf{7}$ showed the diagnostic ${ }^{[15]}$ downfield shift of the signal due to the acylated C-4"' and the concomitant upfield shift of the signals due to the adjacent C- $3^{\prime \prime \prime}$ and C$5^{\prime \prime \prime}$.

Another selective modification of $\mathbf{1}$ was achieved by laccase-mediated oxidation. Laccases are copper-containing oxidases which, in a catalytic cycle, reduce one molecule of oxygen to two molecules of water with the concomitant oxidation of four substrate molecules to give four radicals. ${ }^{[16]}$ Typical substrates of laccases are phenols and aliphatic or aromatic amines, but oxidation of non-phenolic groups like primary alcohols or aromatic methyl groups, is also possible thanks to the auxiliary action of the so-called "mediators" (i.e., TEMPO, HBT, ABTS) ${ }^{[17]}$ The oxidation step is performed by the oxidized form of a suitable mediator, generated by its interaction with the enzyme. Specifically, we have recently shown that a laccase from Trametes pubescens coupled with the chemical mediator TEMPO can catalyze the regioselective oxidation of the primary hydroxy groups of a series of alkyl sugar derivatives to the corresponding glycopyranosiduronates. ${ }^{[18]}$ Asiaticoside carries two primary OH's, the first one on the C-23 of the aglycone moiety and the second one on the internal glucopyranosyl moiety $\left(\mathrm{C}-6^{\prime \prime}\right)$. We were pleased to find that the laccase-TEMPO-mediated oxidation of $\mathbf{1}$ (performed in a water-acetone mixture) was quite selective and a single product $(\mathbf{8})$ could be isolated. Mass analysis indicated that 8 was a monooxidized product (1017 a.m.u., corresponding to the molecular peak of the disodium salt of 8: $\left.\mathrm{M}-\mathrm{H}+2 \mathrm{Na}^{+}\right)$. The ${ }^{13} \mathrm{C}-\mathrm{NMR}$ spectrum of 8 showed that the signal at $61.9 \mathrm{ppm}$, originally due to C-6", was lacking, while in the ${ }^{1} \mathrm{H}-\mathrm{NMR}$ spectrum showed, in addition to a doublet at $3.22 \mathrm{ppm}$ due to H- $5^{\prime \prime}$, the disappearance of the protons due to $\mathrm{CH}_{2}-6^{\prime \prime}$, resonating between 3.90 and $3.65 \mathrm{ppm}$ in the ${ }^{1} \mathrm{H}-\mathrm{NMR}$ spectrum of $\mathbf{1}$, and a single signal remaining in that region, a broad doublet of doublets at 3.88 due to $\mathrm{H}-2^{\prime \prime \prime}$ (easily assigned by COSY correlation).

\section{Conclusion}

It has been shown that enzymes from different classes (specifically, oxidoreductases, trasferases and hydrolas- es) used in different reaction media (water solutions, water solutions containing water-miscible organic solvents, organic solvents) can selectively modify asiaticoside, a complex natural compound carrying several reactive functionalities. An array of different derivatives, with defined chemical structures, was generated from this lead compound exploiting the stereo-, regio- and site-selectivity of these biocatalysts. Worthy of note are the results obtained with the library of $\alpha$-L-rhamnosidases, as they are an additional example of the exploitation of a group of enzymes that are easily generated and isolated and whose synthetic performances can be tuned in situ without need of purification steps.

\section{Experimental Section}

Yeast extract was from OXOID. Casamino acids, $p$-nitrophenyl $\alpha$-L-rhamnopyranoside ( $p$ NP- $\alpha$-L-Rha), $p$-nitrophenyl $\beta$-Dglucopyranoside ( $p$ NP- $\beta$-D-Glc), L-rhamnose, rutin, hesperidin, naringin, $\alpha$-lactalbumin, porcine pancreas lipase (PPL), subtilisin A from Bacillus sp. (subtilisin Calsberg) were from Sigma. Pseudomonas cepacia lipase (PSL) was from Amano. Chromobacterium viscosum lipase (CVL) was from FINNSUGAR. Lipase B from Candida antarctica (Novozym 435) was from Novo Nordisk. Bovine milk $\beta$-1,4-galactosyltransferase $(\beta$ GalT), UDP-galactose (UDP-Gal) and bovine intestine alkaline phosphatase were from Fluka $(\beta-1,4$-galactosyltransferase KIT, no. 59505). Asiaticoside (1) and asiatic acid (4) were a gift from Indena.

Thin-layer chromatography (TLC): precoated silica gel 60 $\mathrm{F}_{254}$ plates (Merck); flash chromatography: silica gel 60 (70230 mesh, Merck). HPLC analyses were carried out using a Jasco 880-PU pump equipped with a Jasco 870-UV detector and a Hewlett-Packard HP-3395 integrator. Enzymatic activities were monitored using a Jasco V-530 UV/VIS spectrophotometer. ${ }^{1} \mathrm{H}$ and ${ }^{13} \mathrm{C}$ NMR spectra at $300 \mathrm{MHz}$ and $75.2 \mathrm{MHz}$ were recorded in $\mathrm{CD}_{3} \mathrm{OD}$ on a Bruker AC-300. Electrospray mass spectrometry (ESI-MS) was recorded with an $\mathrm{LCQ}^{\mathrm{TM}}$ quadrupole ion-trap mass spectrometer (Finnigan MAT, San Jose, CA, USA) equipped with a Nano-ESI source (Protana, Odense, Denmark). Due to the unavoidable presence of $\mathrm{Na}^{+}$ ions during sample preparation and the high alkali-cation affinity of oligosaccharides, all positively charged ions produced were ionized with $\mathrm{Na}^{+}$.

\section{Production of Glycosidases ${ }^{[8]}$}

The strains used in this study originated from the Culture Collection of Fungi (CCF), Department of Botany, Charles University, Prague, and from the Culture Collection of the Institute of Microbiology (CCIM), Prague, Czech Republic. The cultivation medium contained [g/L]: $\mathrm{KCl}, 0.5 ; \mathrm{KH}_{2} \mathrm{PO}_{4}, 15 ; \mathrm{NH}_{4}$ $\mathrm{Cl}, 4$; yeast extract, 5 ; casamino acids, 1 . Before sterilization, the medium was supplemented by the specific inducer ( $\mathrm{L}-$ rhamnose, rutin, hesperidin and naringin, $5 \mathrm{~g} / \mathrm{L}$ ) and $1 \mathrm{~mL} / \mathrm{L}$ of trace element Vishniac solution, ${ }^{[20]}$ the $\mathrm{pH}$ was adjusted to 6.0 and after sterilization $\mathrm{MgSO}_{4} \cdot 7 \mathrm{H}_{2} \mathrm{O}$ sterile solution $(10 \% \mathrm{w} / \mathrm{v}, 5 \mathrm{~mL} / \mathrm{L})$ was added. Conical flasks $(500 \mathrm{~mL})$ with $100 \mathrm{~mL}$ of medium were inoculated with $0.5 \mathrm{~mL}$ of a spore sus- 
pension in $0.1 \%(\mathrm{v} / \mathrm{v})$ Tween 80 solution and cultivated on a rotary shaker at $200 \mathrm{rpm}$ and $28^{\circ} \mathrm{C}$. To test constitutive production of $\alpha$-L-rhamnosidases, each strain was cultured in the same medium, but replacing the inducer with respective amounts of casamino acids.

Clear filtrate samples for each culture were collected daily and submitted to the $\alpha$-L-rhamnosidase activity assay. Cultures were filtered when the maximum activity of $\alpha$-L-rhamnosidase was reached, typically after 5-10 days of growth. Crude $\alpha-\mathrm{L}-$ rhamnosidase preparations were obtained as ammonium sulfate precipitates ( $80 \%$ saturation) and stored in saturated ammonium sulfate solution at $4{ }^{\circ} \mathrm{C}$.

\section{Glycosidase Activity Assays}

$\alpha$-L-Rhamnosidase and $\beta$-D-glucosidase activities were assayed spectrophotometrically using $p \mathrm{NP}-\alpha-\mathrm{L}-\mathrm{Rh}$ a and $p \mathrm{NP}-\beta-\mathrm{D}-\mathrm{Glc}$ as substrates, respectively. One unit of the respective glycosidase activity was defined as the amount of enzyme releasing $1 \mu \mathrm{mol}$ of $p$-nitrophenol per minute at $\mathrm{pH} 6.0$ and $35^{\circ} \mathrm{C}$.

\section{Screening of the Library for Asiaticoside Hydrolysis}

The screening of the $\alpha$-L-rhamnosidase library for asiaticoside hydrolysis was performed on a $2 \mathrm{mg} / \mathrm{mL}$ asiaticoside solution in $50 \mathrm{mM}$ potassium phosphate buffer, $\mathrm{pH}$ 6.0. A sample of each preparation of the enzyme library $(5 \mu \mathrm{L}$, minimum 6 Units) was added to $1 \mathrm{~mL}$ of substrate solution and the mixtures were incubated at $35^{\circ} \mathrm{C}$ for $48 \mathrm{~h}$. The reactions were monitored by TLC [AcOEt-MeOH- $\mathrm{H}_{2} \mathrm{O}=8: 3: 0.5 ; \mathrm{R}_{\mathrm{f}}$ : asiaticoside (1), 0.10; L-rhamnose, 0.21; D-glucose, 0.07; asiatic acid $(4), 0.37]$ with the molybdate reagent $\left[\left(\mathrm{NH}_{4}\right)_{6} \mathrm{Mo}_{7} \mathrm{O}_{24} \cdot 4 \mathrm{H}_{2} \mathrm{O}\right.$, $42 \mathrm{~g} ; \mathrm{Ce}\left(\mathrm{SO}_{4}\right)_{2}, 2 \mathrm{~g} ; \mathrm{H}_{2} \mathrm{SO}_{4}$ conc., $62 \mathrm{~mL}$; made up to $1 \mathrm{~L}$ with deionized water].

\section{Preparative Synthesis of Derhamno-Degluco- Asiaticoside (3)}

The synthesis of $\mathbf{3}$ was accomplished by dissolving asiaticoside $(\mathbf{1}, 75 \mathrm{mg})$ in $25 \mathrm{~mL}$ of $50 \mathrm{mM}$ potassium phosphate buffer, $\mathrm{pH} 6.0$ and adding $10 \mathrm{U}(200 \mu \mathrm{L}$ of a $50 \mathrm{U} / \mathrm{mL}$ suspension $)$ of the $\alpha$-L-rhamnosidase from Fusarium oxysporum CCF 906 (inducer: rutin). The reaction was incubated at $35^{\circ} \mathrm{C}$ and monitored by TLC (AcOEt-MeOH- $\left.\mathrm{H}_{2} \mathrm{O}=8: 3: 0.5\right)$ and HPLC analyses [reverse-phase analytical column Lichrospher ${ }^{\circledR}$ RP$18,5 \mu \mathrm{m}, 4 \times 125 \mathrm{~mm}$, Merck; mobile phase: $\mathrm{H}_{2} \mathrm{O}$ (A) $\mathrm{CH}_{3} \mathrm{CN}$ (B): $0^{\prime}-60^{\prime}, 80 \%$ v/v A; $120^{\prime}, 60 \%$ v/v A; 150 ' $80 \%$ $\mathrm{v} / \mathrm{v}$ A; flow rate: $1 \mathrm{~mL} / \mathrm{min}$, UV detector: $205 \mathrm{~nm}$; samples: $100 \mu \mathrm{L}$ of the reaction mixture were lyophilized and dissolved in $20 \mu \mathrm{L}$ of $\mathrm{H}_{2} \mathrm{O}: \mathrm{EtOH}=1: 1$, injection volume: $10 \mu \mathrm{L}$, retention times: 1, $35 \mathrm{~min} ; \mathbf{3}, 79 \mathrm{~min}$; asiatic acid (4), $110 \mathrm{~min}$. After $48 \mathrm{~h}$, the product was recovered by extraction with AcOEt and the solvent was evaporated. The crude residue $(170 \mathrm{mg})$ was purified by flash chromatography (eluent: $\mathrm{CHCl}_{3}-\mathrm{MeOH}-\mathrm{H}_{2}$ $\mathrm{O}=8: 2: 0.1)$ to give 3 ; yield: $25 \mathrm{mg}(47 \%)$.

\section{Preparative Synthesis of Derhamno-Asiaticoside (2)}

Synthesis of $\mathbf{2}$ was accomplished as described for $\mathbf{3}$, but in the presence of $15 \% \mathrm{w} / \mathrm{v}$ glucose in order to inhibit contaminating $\beta$-D-glucosidase activities in situ. The reaction was monitored by TLC and HPLC analyses (same conditions used for $\mathbf{3}$, retention times: 1, $35 \mathrm{~min} ; \mathbf{2}, 43 \mathrm{~min} ; \mathbf{3}, 79 \mathrm{~min}$ ). After $48 \mathrm{~h}, 4.25 \mathrm{~g}$ of $\mathrm{NaCl}$ were added to the reaction mixture and the product was extracted with AcOEt and the solvent was evaporated. The crude residue $(343 \mathrm{mg}$ ) was submitted to two subsequent flash chromatography columns (eluent: $\mathrm{CHCl}_{3}-\mathrm{MeOH}-\mathrm{H}_{2} \mathrm{O}=$ $8: 2: 0.1$ and $\left.\mathrm{CHCl}_{3}-\mathrm{MeOH}-\mathrm{H}_{2} \mathrm{O}=8: 3: 0.4\right)$ to give 2 ; yield: $28 \mathrm{mg}(46 \%)$.

\section{Galactosylation of 2 and 3}

Compound 2 (28 mg) or $\mathbf{3}(25 \mathrm{mg})$ was dissolved into $2 \mathrm{~mL}$ of DMSO. $7 \mathrm{~mL}$ of reaction solution, containing $50 \mathrm{mM}$ TRIS/ $\mathrm{HCl}, \mathrm{pH} 7.4,10 \mathrm{mM} \mathrm{MnCl}_{2}, 7.9 \mathrm{mg} / \mathrm{mL}$ UDP-Gal and $0.28 \mathrm{mg} / \mathrm{mL} \alpha$-lactalbumin, and $1 \mathrm{~mL}$ of enzymatic solution [50 mM TRIS/HCl, pH 7.4, 2 U/mL bovine milk $\beta$-1,4-galactosyltransferase $(\beta \mathrm{GalT}), 66 \mathrm{U} / \mathrm{mL}$ bovine intestine alkaline phosphatase] were then added to the substrate solutions and the reactions were incubated at $35^{\circ} \mathrm{C}$. TLC $\left(\mathrm{CHCl}_{3}-\mathrm{MeOH}-\right.$ $\left.\mathrm{H}_{2} \mathrm{O}=8: 3: 0.5\right)$ and HPLC analyses [reverse-phase analytical column Lichrospher ${ }^{\circledR}$ RP-18, $5 \mu \mathrm{m}, 4 \times 125 \mathrm{~mm}$, Merck; mobile phase: $\mathrm{H}_{2} \mathrm{O}(\mathrm{A}), \mathrm{CH}_{3} \mathrm{CN}(\mathrm{B}): 0^{\prime}-60^{\prime}, 80 \%$ v/v A; $120^{\prime}, 60 \% \mathrm{v} / \mathrm{v}$ A; $150^{\prime}, 80 \% \mathrm{v} / \mathrm{v}$ A; flow rate: $1 \mathrm{~mL} / \mathrm{min}$, UV detector: $205 \mathrm{~nm}$; injection volume: $2 \mu \mathrm{L}$, retention times: 2, $54.2 \mathrm{~min}$; 3, $80.2 \mathrm{~min} ; \mathbf{5}, 41.1 \mathrm{~min} ; \mathbf{6}, 75.9 \mathrm{~min}]$ were carried out at scheduled times. After $72 \mathrm{~h}$, the products were purified by flash chromatography (eluent: $\mathrm{CHCl}_{3}-\mathrm{MeOH}-\mathrm{H}_{2} \mathrm{O}=8: 3: 0.4$ ) to give 5 (yield: $16 \mathrm{mg}, 47 \%$ ) or $6(10 \mathrm{mg})$. As this last product contained traces of uridine (as shown by TLC, eluent AcOEt-MeOH$\mathrm{H}_{2} \mathrm{O}=7: 3: 0.5$ ), it was further purified by flash chromatography (eluent: $\mathrm{CHCl}_{3}-\mathrm{MeOH}-\mathrm{H}_{2} \mathrm{O}=8: 2: 0.3$ ) to give pure 6 (yield: $3 \mathrm{mg}, 9 \%$ ).

\section{Acylation of Asiaticoside by Lipases and Proteases}

Five different hydrolases [the protease subtilisin Calsberg and the lipases from porcine pancreas (PPL), Pseudomonas cepacia (PSL), Chromobacterium viscosum (CVL) and Candida antarctica (Novozym 435)] were screened for their ability to acylate $\mathbf{1}$ in the presence of THF and vinyl acetate. Before use, PPL was adsorbed on Celite and subtilisin Calsberg on $\mathrm{K}_{2} \mathrm{HPO}_{4}$. The reactions were monitored by TLC $\left(\mathrm{CHCl}_{3}-\right.$ $\left.\mathrm{MeOH}-\mathrm{H}_{2} \mathrm{O}=10: 5: 1\right)$. The formation of products was observed only when using Novozym 435 and PSL, therefore the reactions with these enzymes were scaled-up in order to recover and characterize the products.

Two substrate solutions each containing 1 (200 mg) dissolved in $18 \mathrm{~mL}$ of dry THF and $2 \mathrm{~mL}$ of vinyl acetate as acylating agent were prepared. $150 \mathrm{mg}$ of Novozym 435 or $1 \mathrm{~g}$ of PSL on Celite were then added, respectively, and the mixtures were shaken at $250 \mathrm{rpm}$ and $45^{\circ} \mathrm{C}$. The reactions were monitored daily by TLC and, after 3 days, fresh immobilized enzymes (150 mg of Novozym 435 and $400 \mathrm{mg}$ of PSL, respectively) and vinyl acetate $(1 \mathrm{~mL}$ to each reaction) were added. After 7 days, products were recovered by filtration and purified by flash chromatography (eluent: $\mathrm{CHCl}_{3}-\mathrm{MeOH}-\mathrm{H}_{2} \mathrm{O}=$ 
$10: 3: 0.3)$. The Novozym 435 reaction gave $44^{\prime \prime \prime}-O$-acetylasiaticoside (7; yield: $122 \mathrm{mg}, 59 \%$ ), whereas the PSL reaction gave 7 (47 mg, 23\%) and a mixture of $2^{\prime \prime \prime}$ - and $3^{\prime \prime \prime}$ - $O$-acetylasiaticoside (yield: $38 \mathrm{mg}, 18 \%$ ).

\section{Oxidation of Asiaticoside by Laccases}

Asiaticoside (1; $101 \mathrm{mg}, 0.1 \mathrm{mmol}$ ) was dissolved in a mixture of $15 \mathrm{~mL}$ acetone and $35 \mathrm{~mL}$ acetate buffer $(20 \mathrm{mM} \mathrm{pH} 4.5)$. Following the addition of TEMPO ( $3.5 \mathrm{mg}, 0.2$ equivs.) and $2 \mathrm{~mL}$ of a $26 \mathrm{U} / \mathrm{mL}$ solution of a laccase from Trametes pubescens, the reaction mixture was mildly shaken at room temperature for 7 days. The water solution was evaporated and the crude residue purified by silica flash chromatography (eluent: AcOEt-MeOH- $\left.\mathrm{H}_{2} \mathrm{O}=10: 3: 1\right)$ to give 8; yield: $25 \mathrm{mg}$ (26\%).

\section{Supporting Information}

Characterization data for compounds $\mathbf{1 - 8}$ are available in the Supporting Information.

\section{Acknowledgements}

We gratefully thank Dr. Roland Wohlgemuth (Fluka) for a generous gift of the GalT Kit and Andrea Pišvejcová (Institute of Microbiology, Prague) for her valuable technical assistance in the preparation of the rhamnosidase library. This work was partly supported by a bilateral project between Italy and Portugal sponsored by the respective National Council of Research (CNR and GRICES), by COST chemistry D25/0001/02 (OC $D 25.002)$ and by a bilateral project between Italy and the Czech Republic (NATO Collaborative project No. LST.CLG.980125).

\section{References}

[1] R. Ikan, Naturally Occurring Glycosides, John Wiley \& Sons, Chicester, 1999.

[2] V. Křen, L. Martínková, Curr. Med. Chem. Rev. 2001, 8 , 1313-1338.

[3] L. Lu, K. Ying, S. Wei, Y. Liu, H. Lin, Y. Mao, Br. J. Dermatol. 2004, 151, 571-578.

[4] J. H. Sampson, A. Raman, G. Karlsen, H. Navsaria, I. M. Leigh, Phytomedicine 2001, 8, 230-235.
[5] A. Shukla, A. M. Rasik, B. N. Dhawan, Phytother. Res. 1999, 13, 50-54.

[6] I. Mook-Jung, J. E. Shin, S. H. Yun, K. Huh, J. Y. Koh, H. K. Park, S. S. Jew, M. W. Jung, J. Neurosci. Res. 1999, 58, 417-425.

[7] a) A. S. Bommarius, B. R. Riebel, Biocatalysis, WileyVCH Verlag, Weinheim, 2004; b) S. Riva, Curr. Opin. Chem. Biol. 2001, 5, 106-111.

[8] D. Monti, A. Pišvejcová, V. Křen, M. Lama, S. Riva, $B i$ otechnol. Bioeng. 2004, 87, 763-771.

[9] a) E. G. Berger, J. Rohrer, Biochimie 2003, 85, 261-274; b) R. Ohrlein, in: Biocatalysis: from Discovery to Applications, (Ed: W. D. Fessner), Springer Verlag, Heidelberg, 2004, pp. 228-266.

[10] a) S. Gebhardt, S. Bihler, M. Schubert-Zsilavecz, S. Riva, D. Monti, L. Falcone, B. Danieli, Helv. Chim. Acta 2002, 85, 1943-1959; b) B. Danieli, L. Falcone, D. Monti, S. Riva, S. Gebhardt, M. Schubert-Zsilavecz, J. Org. Chem. 2001, 66, 262-269; c) S. Riva, D. Monti, M. Luisetti, B. Danieli, Ann. N. Y. Acad. Sciences 1998, 864, $70-80$.

[11] a) L.Tarantini, D. Monti, L. Panza, D. Prosperi, S. Riva, J. Mol. Cat. B: Enzymatic 2001, 11, 343-348; b) S. Riva, B. Sennino, F. Zambianchi, B. Danieli, L. Panza, Carbohydr. Res. 1998, 305, 525-531.

[12] G. Carrea, S. Riva, Angew. Chem. Int. Ed. 2000, 39, 2227-2254, and references cited therein.

[13] S. Riva, J. Mol. Cat. B: Enzymatic 2002, 19-20, 43-54.

[14] B. Danieli, M. Luisetti, G. Sampognaro, G. Carrea, S. Riva, J. Mol. Cat. B: Enzymatic 1997, 3, 193-201.

[15] K. Hoshimoto, Y. Itatani, Y. Tsuda, Chem. Pharm. Bull. 1980, 28, 2065-2076.

[16] a) S. G. Burton, Curr. Org. Chem. 2003, 7, 1317-1331; b) A. M. Mayer, R. C. Staples, Phytochemistry 2002, 60, 551-565; c) E. I. Solomon, U. M. Sundaram, T. E. Machonkin, Chem. Rev. 1996, 96, 2563-2605.

[17] A. M. Barreca, B. Sjogren, M. Fabbrini, C. Galli, P. Gentili, Biocatal. Biotrans. 2004, 22, 105-112, and references cited therein.

[18] M. Marzorati, B. Danieli, D. Haltrich, S. Riva, Green Chem. 2005, in press.

[19] T. V. Sung, C. Lavaud, A. Porzel, W. Steglich, G. Adam, Phytochemistry 1992, 31, 227-231.

[20] V. Vishniac, A. Santer, Bacteriol. Rev. 1957, 21, 195-213. 